\title{
EL LÉXICO DEL TABÚ SEXUAL EN LAS OBRAS LEXICOGRÁFICAS COSTARRICENSES
}

\author{
Annette Calvo Shadid
}

\begin{abstract}
RESUMEN
En este artículo, se presentan las principales obras lexicográficas que han incluido el léxico sobre el tabú sexual en el español de Costa Rica. Se presenta una cronología de estos estudios, se señalan las diferencias entre ellas y se establecen dos períodos para su estudio.

Palabras clave: tabú sexual, lexicografía, español de Costa Rica, lingüística.
\end{abstract}

\begin{abstract}
This article presents a selection of main lexicographic works that includes sexual taboo vocabulary in Costa Rican Spanish. A chronology of these works is shown, it points out the differences between them, and two periods for its study are proposed.

Key words: sexual taboo, lexicography, Costa Rican Spanish, linguistics.
\end{abstract}

\section{Introducción}

La autora del presente artículo, al haber realizado una investigación sociolingüística sobre el tabú sexual en el español de Costa Rica finalizada en el 20081, analizó el uso de diez lexías de connotación sexual probadas previamente en un estudio piloto. Se determinó que cinco de las lexías correspondían al español general (huevos, tetas, culo, puta, picha) y cinco de ellas se consideraron regionalismos (mico, culear, regarse, playo, tortillera). En el aspecto

Dra. Anette Calvo Shadid. Decana de Facultad de Letras. Universidad de Costa Rica. Correo electrónico: acalsha@yahoo.com.mx

Recepción: 21- 03- 2011

Aceptación: 29- 04- 2011 
sociolingüístico, los estudios sobre el tabú lingüístico, y en especial los relacionados con el tabú sexual, han sido poco estudiados en el ámbito hispánico ${ }^{2}$. En particular, en el español de Costa Rica no ha habido, hasta el momento, ninguna otra investigación aparte de Calvo Shadid (2008), la cual aborde el tabú lingüístico de tipo sexual de esa forma.

Respecto de las lexías tabuizadas, la autora de este artículo buscó cuáles de ellas y otros términos con referencia a lo sexual se habían registrado en las obras lexicográficas costarricenses como diccionarios, glosarios y léxicos. Aun cuando el vocabulario relacionado con el tabú sexual hubiera sido registrado en dichas obras, la autora consideró que era indispensable extraerlas de las fuentes que las hubieran incluido para mostrar sus referencias con la mayor exactitud y las marcas lexicográficas utilizadas en cada una de las fuentes; observar si se podían establecer períodos entre las obras, y determinar a partir de qué momento se empezaron a registrar lexías tabuizadas.

\title{
2. El léxico tabú en las obras lexicográficas costarricenses
}

Las referencias se inician con el maestro Gagini (1892) en la obra Diccionario de barbarismos y provincialismos de Costa Rica. En ese texto, se observa claramente la posición de desestima que tenía el autor en esa primera época por las variedades autóctonas. Mostraba una posición claramente unionista y purista, con la idea de que el español de América debía ser según el modelo peninsular, lo cual incluía la literatura:

\begin{abstract}
La Lengua castellana ha experimentado tales modificaciones en el Nuevo Mundo, son tan numerosas las corruptelas, los neologismos, extranjerismos y alteraciones sintácticas con que la desfigura el vulgo, que en muchos lugares no es ya sino una caricatura grotesca de aquella habla divina de Garcilaso, Calderón y Cervantes. Por otra parte, esos matices locales contribuyen sobre modo a romper la unidad del idioma común de nuestras Repúblicas, preparando la formación de dialectos y dificultando el comercio de ideas. (Gagini 1892: I)
\end{abstract}

No es la idea de esta investigación abordar los enfoques planteados por los autores en las diversas obras, ni se considera necesario, puesto que después de esta primera obra de Gagini, las demás que se incluyen es este estudio, incluyendo el posterior Diccionario de Costarriqueñismos de este mismo autor, presentan definiciones más descriptivas, con pocos juicios de valor, objetivas y utilizando las técnicas lexicográficas establecidas para ese tipo de obras.

En la primera época de Gagini, la definición presentaba algunas veces comentarios y disculpas del autor por presentar palabras que se consideraban soeces; por ejemplo ${ }^{3}$ :

Cerote. No se alarmen nuestros lectores al ver estampada en esta obrilla tan fea palabra: abran el Diccionario oficial y se convencerán de inmediato de lo infundado de sus recelos "Cerote. (De cera) Mezcla de pez y cera de que usan los zapateros para encerar los hilos con que cosen el calzado". Hácese también de pez y aceite; mas es de inferior calidad". Lo que aquí designamos con ese nombre, y que no nos atrevemos a describir, se llama en España zurullo. (Gagini 1892: 132)

La única palabra en Gagini (1892: 230) con referencia al ámbito de la conducta sexual es la siguiente:

Chuchinga. Considérase este adjetivo como muy grosero y rara vez se oye entre personas educadas.

Aplicase al hombre afeminado o amujerado, al que imita los modales de las mujeres, usa prendas propias de estas, etc. y también al que los españoles llaman "Perico entre ellas". Se toma generalmente en mala parte.

Otras palabras como coger, mamada y pararse que en la actualidad presentan acepciones sexuales, se definen en Gagini (1892: 142, 428, 482) como sigue: 
Coger. "Coger por una calle, coger para el monte, etc." son frases que oímos a diario a nuestros compatriotas; en ellas, coger está empleado por dirigirse, encaminar, tirar. El Diccionario no autoriza esta acepción; pero es indudablemente castellana, aunque ya anticuada.

Mamada. "Tiempo que la criatura mama", dice el Diccionario; pero en toda América se toma esta palabra por ganga, canonjía, prebenda.

Pararse. En toda Hispanoamérica se da a este verbo la acepción de levantarse, alzarse, ponerse en pie o de pies; pero lo que realmente significa es detenerse, cesar de moverse.

Como se puede observar, el recato y la "corrección” en el uso del idioma eran valores deseables en los diccionarios de esa época.

Posteriormente, Gagini (1919/75) publica, con otro enfoque, el Diccionario de costarriqueñismos. En la página web de la Academia Costarricense de la Lengua ${ }^{4}$, se cita sobre esta obra: "El Diccionario de costarriqueñismos, de Carlos Gagini, publicado en 1919, es la obra cumbre de este destacado lingüista, uno de los fundadores de la Academia Costarricense de la Lengua. Es uno de los trabajos lexicográficos más importantes y un punto de referencia ineludible para los estudios sobre el español de Costa Rica”. El autor, no obstante, incluye muy poco vocabulario de tipo sexual. Registra las siguientes unidades léxicas:

Culiolo.- Sodomita. Aunque parece castellano es azteca: cuiloni, que significa lo mismo.

Chuchinga.- Afeminado, maricón, que imita los modales y aún el traje de las mujeres. Es término muy grosero. Tal vez tenga relación con el quechua 'chucchina', recoger las sobras 5 .

Fondillo.- Asentaderas.

Fusil.- Ano.

Mujer de la calle.- Nombre con que la buena sociedad distingue a las prostitutas, mujeres públicas, de la vida airada, rameras, pelanduscas, pendangas, peliforras o mozas del partido. Es denominación muy apropiada.

Algunos términos que actualmente presentan una acepción sexual, como coger, panocha, tortillera, platanazo y su sinónimo plátano, en Gagini (1919/1975) tampoco se contemplan aún con tales acepciones. Por ejemplo, cita:

Coger.- [...] Coger en la acepción de tomar, dirigirse, encaminarse, es sencillamente un arcaísmo. [...] La expresión de Gagini: Coger la calle. Tratándose de una mujer, prostituirse, es la única que registra con connotación sexual en esta entrada.

Panocha.- "Panocha o panoja es en el dicc. La mazorca de maíz. Entre nosotros es la arepa grande y gruesa hecha de los granos de la mazorca cuando está tierna [...]" (Uribe Diccionario Abreviado: 350) En C.R. se da también este nombre a la mujer pequeña y gruesa, que el dicc. llama pandorga.

Platanazo.- Batacazo, costalada.

Plátano.- Muchas son las variedades que esta musácea se cultivan en C.R., entre las cuales citaremos el plátano macho, una de las más comunes y grandes, y el plátano pera o manzana, muy pequeño y de sabor y olor deliciosos.

Tortillera.- Mujer que tiene por oficio hacer o vender tortillas.

Por lo anterior, se podría suponer que a la fecha de edición del diccionario (1919), las palabras anteriores o bien no tenían aún acepciones sexuales, o bien simplemente no se consignaron tales acepciones.

En su tesis doctoral sobre el argot costarricense, Villegas (1953) también registra pocas palabras con connotaciones sexuales, aun cuando el argot se refiere a un léxico no normativo. Se registran las siguientes: 
CHUCHINGA. Ref. Gagini.

COGER LA CALLE. Por lo que nos dice Gagini “aplicado a una mujer quería decir prostituirse". Hoy en día, aplicado tanto a hombres como a mujeres quiere decir solamente "vagabundear" o "andar por la calle sin hacer nada".

MUJER DE LA CALLE. Prostituta.

PÁJARO adj. Afeminado. "No me gusta salir con ellos porque dicen que todos son un poco pájaros".

Otros términos que en la actualidad presentan una connotación sexual aparecen también en Villegas (1953), pero con acepciones no sexuales. Por ejemplo:

CARRACO adj. Rústico, campesino. "Ese hombre no es más que un carraco".

COGIDA f. Sorpresa. "Sin chance de ocultarme y no me quedó más remedio que disimular la cogida". Fal.31 [Ejemplo de 'Mamita Yunai'].

PANOCHA f. Torta. "En casa antes hacían panochas de harina, de arroz y a veces de maíz y queso". M (C. Rica, Chile). G.S.

ZORRA f. SER ZORRA. v. Ser muy inútil o no tener habilidad para algo. "No queremos jugar con Pepe porque es muy zorra".

Como se puede observar en Villegas, las palabras anteriores que en la actualidad no solo presentan una acepción sexual sino que se utilizan principalmente con tal acepción, no se registran de esa manera. Estos dos primeros autores, es decir, tanto en la segunda década del siglo XX con Gagini como a mediados con Villegas, prácticamente no registran palabras con acepciones sexuales. Así, para precisar si algunas de las acepciones de tipo sexual se utilizaban tanto a inicios como a mediados del siglo XX, habría que elaborar un estudio más profundo en la literatura o en muchos otros textos de la época, que incluyera vocabulario soez o sexual, o verificar con informantes de la tercera generación su opinión respecto del uso del vocabulario del tabú sexual durante esa época, lo cual no es un objetivo en este artículo.

El Glosario del hampa en Costa Rica, de Sánchez Alvarado ${ }^{6}$ (1960), es interesante porque recoge los términos del hampa de la antigua Colonia Agrícola Penal de San Lucas. Este es un léxico bastante rico por la naturaleza de los comentarios del autor. Sin embargo, no recurre a criterios lexicográficos para la elaboración de la obra ${ }^{7}$.

Registra numerosos términos tabuizados, algunos de los cuales tienen que ver con las lexías aquí tratadas. Se citan a continuación los que tienen que ver, de alguna forma, con las que se incluyen en la presente investigación. Se registran con sus peculiares definiciones y comentarios del autor.

ABRIR las tapas: Dejarse tomar por otro hombre. "Fulano abre las tapas por un peso".

ABRIR las piernas: La mujer que se entrega al hombre. Dice la prostituta: "me le abrí de piernas porque lo amaba mucho".

ACABAR: Eyacular en el acto sexual. En el hampa se le llama "cabada" al líquido o esperma de la eyaculación, de manera que "acabar" viene siendo algo así como "echar cabada". Se dice acabé, acabo, acabando, etc. Las mujeres de la vida no gustan de los hombres que tardan mucho tiempo efectuando el coito y entonces les reclaman "¿no va a acabar? Estoy cansada”.

AJO el. El recto, se refiere al de la mujer. Al del hombre le dicen "el ojo".

ALETEO: Tendencias a la homosexualidad. Si una persona al hablar pone tonos de mujer; si los ademanes son sexuales, el hampa los llama "aleteos". Viene de "pájaro" que es como se denomina al homosexual. También se define como la provocación del homosexual, como hacerse el amor entre hombres. El hampa, poco amiga de la poesía y de las palabras bellas, cuando encuentra una persona de fácil expresión, lo trata de denigrar diciendo que es un aleteador. El léxico del hampa, como se ha de ver, se compone de 
palabras rudas, torcidas, y cuando son correctas en su pronunciación, le inculca el énfasis de desprecio o repugnancia y es cuando las pronuncia cortadas, con voces casi femeninas.

ALOSO: Un hombre con tendencias homosexuales.

AMARRAR UN PERRO: Cohabitar con una mujer de la vida y no pagarle; hacerle una jugada a una mujer de la vida. También se usa como usar de otro hombre, un homosexual pasivo y no pagarle. De ahí la costumbre de casi todas las prostitutas populares de solicitar el precio por adelantado. "A mí no me amarra un perro nadie, déme por adelantado".

ANCIANA la: Una mujer de la vida veterana, muy conocida, aunque sea joven.

ANIMAL el: el sexo femenino, la vagina.

AVE: un homosexual.

BAJO volar: Tener procederes de homosexual. "El señor siempre anda volando bajo".

BANANO el: El pene.

BICHO el: El sexo de la mujer.

BIMBA dar: Violar a una mujer o a un hombre o ejecutar una relación sexual. "A ese (o esa) yo le he dado bimba".

BIGUAM el: El pene.

BISAGRA: Sexo de la mujer.

BOLLO el: El sexo de la mujer ${ }^{8}$.

BORRADOR el: El recto.

BOTÓN: El recto.

BOTELLA: El pene.

BRINCAR: Realizar el coito.

CABADA: Esperma de la eyaculación del hombre. Es curioso saber que gran cantidad de prostitutas tienen el firme convencimiento de que ellas también eyaculan como el hombre.

CABEZA la: El pene. También la llaman "cabezona" "cabezota”, "cabezuda”.

CACHERO: Se le llama así al sodomo activo. Los cacheros no pueden vivir en la cárcel si no es con un hombre al que usaban indistintamente en forma activa o pasiva. Sus víctimas son los menores.

CACHO: El pene.

CAPADA: Se le llama a la mujer que le gusta vivir solo con mujeres. Para esta mujer vale lo mismo que se ha dicho sobre el homosexual. Ellas sienten amor por otra mujer y odian al hombre. Se llama así a algunas mujeres de la vida que para no tener hijos llegan hasta a hacerse una operación que denominan "capar". El lector comprenderá nuestra reserva sobre esta operación.

CARROCERÍA: [...] También se usa para indicar la parte trasera de una mujer. "María tiene buena carrocería".

CARIOCA la: Sexo femenino.

CARRUCHA la: Sexo masculino.

CATALINA la: El sexo de la mujer.

CABOLLA la: El pene.

CENEIDAS: Sexo de mujer.

CLAVO: El pene.

CLASE PUTA: Mujer de la vida de primera calidad.

COMER: [...] Algunas veces tiene carácter sexual: "A esa (o ese) yo me lo comín".

CONO el: El pene. 
COÑO: Vagina.

COGER: Hacer uso sexual de una persona. "Esa mujer está cogida", por decir que es una mujer que ha tenido relación sexual con un hombre.

CORNETA la: El pene.

COPITOS: Testículos.

CULERO: El homosexual pasivo.

CULEBRA la: El pene.

CULANTRO: Parte trasera del cuerpo humano.

VENDER EL CULANTRO (sic): Es para definir al homosexual que hace negocio con su trasero, que se vende.

CULO: Trasero.

CULIOLO: El homosexual.

CULIADOR: El hombre que vende su cuerpo. También "culiadora" a la mujer que se vende.

CULIAR: Efectuar el coito.

CULO: La vagina.

CHANCHO ojo de: Vagina.

CHAROLES: Senos de mujer.

CHAVALITO: Muchacho joven que le sirve de mujer (sic) a otro.

CHICHAS: Senos de mujer.

CHILE el: El pene.

CHINEO: Amor descarado entre hombres.

CHINGO: La vagina.

CHIQUITO: La vagina.

CHITO: La vagina.

CHUCHA: Vagina. En Panamá es un insulto grande.

CHUCHEAR: Efectuar el coito.

CHUNCHE: Vagina.

CHUCHO: Vagina.

DARLO: Vender el cuerpo sexualmente. "A esa le gusta darlo".

DESPEGAR: Terminar el acto sexual.

DOS EQUIPOS que juega en: Un homosexual activo y pasivo "juega en los dos equipos".

ECHAR SORIAS: Relación sexual entre mujeres.

ENCENDER: El acto sexual.

ESPALOMAR: El coito con una mujer a un hombre (sic). El hampa llama "paloma".

EMPAQUETAR: Realizar el coito con otro hombre.

EMPIERNAR: Dormir con una mujer; pasar la noche con otro hombre; realizar el acto sexual [...].

EMPALAR: Hacer el acto sexual con hombre o mujer.

EMBARRAR: [...] Ejecutar el acto sexual con otro hombre.

ENVERGAR: Hacer el acto sexual. "Verga" es pene.

ENVERDURAR: Ejecutar el coito. 
ENTUBAR: Tener relaciones sexuales con otro hombre.

FEO el: La vagina.

FUIME: Palabra que se indica para expresar que se ha sentido el orgasmo o que se haya eyaculado sin quererlo, quizás por tener pensamientos morbosos...

GABACHO el: El pena, la vagina.

GARROTE: El pene.

GUSTA EL DULCE que le: Que es homosexual.

GÜECO (hueco): Vagina; [...] hombre que ha tenido relaciones sexuales pasivas.

GUINDAJO: El pene.

HEDIONDO el: La vagina.

HUÉRFANOS los: Los testículos.

IDO: Que ya ha terminado el orgasmo.

IR: El orgasmo.

IZQUIERDO: Homosexual.

IGUANA la: La vagina, el pene.

JETA: [...] Vagina.

MATRIMONIO: Hombre y hombre que viven juntos.

ME ESTOY YENDO: Estoy sintiendo el orgasmo.

MENUDEAR: Hombre o mujer que entrega el cuerpo sexualmente por un precio inferior al acordado entre los demás.

METERLA: Hacer el acto sexual con una mujer u otro hombre.

MICO: Vagina.

MONO el: La vagina.

MOSTAZA: Se le llama así a las relaciones homosexuales. "A ese le gusta la mostaza".

NANCE el: El recto.

NELFIS: Nalgas.

NENA: Mujer prostituta recién ingresada al gremio y que aún no tiene relación con el hampa.

OJO DE CHANCHO: El recto, la vagina.

PÁJARO: Homosexual.

PAJARRACO: Homosexual viejo con eternas manías de conquista.

PALITO el: El coito.

PALO el: El pene.

PALOMA la: El pene.

PALOMO el: El pene. Hombre dado a la homosexualidad.

PANAL el: La vagina.

PANCHO el: La vagina.

PANQUEQUES: Las nalgas.

PAPAYA la: La vagina.

PANOCHO el: La vagina.

PAPO el: El pene, la vagina. 
PASA la: El recto.

PAYASO el: El pene, la vagina.

PELUDA la: El pene, la vagina.

PEPA la: El clítoris de la vagina (sic). La vagina.

PERRA la: Mujer de la vida.

PEJIBAYE el: El pene.

PICHA la: El pene.

PICAPORTE el: La vagina.

PICHUDO: Que tiene el pene grande. Muy bueno. Excelente.

PICHAR: Hacer el coito.

PLAYA: Mujer de la vida.

PLAYO: Homosexual.

PLAYITO: Joven homosexual.

PLUMÍFERO: Homosexual.

PUTA: Mujer de la vida.

PUTILLA: Mujer de la vida de formas feas, flacas, desgarbadas [...].

POLVO un: El coito.

POLVO le gusta el: Recluso joven dado a vicios homosexuales.

POLVASAL (sic) hecho un: Convertido en un homosexual pasivo.

PONEDOR: [...] Que ejerce comercio sexual con otro hombre.

POZO el: La vagina.

PRENSARLO: Hacer el acto sexual un hombre activo con uno pasivo.

PRENSARLA: Realizar el coito con una mujer.

PROSTITUTO: Hombre que vende el cuerpo. Homosexual.

PURSIANA: Mujer de la vida.

PUTEAR: Ejercer la prostitución.

PUTA: Mujer de la vida.

PUTO: Hombre que se vende.

PUTONA: Prostituta vieja, arruinada.

QUEQUES: [...] Las nalgas.

QUEQUITOS: Nalgas.

RABO: Parte posterior. Asentaderas. Culo.

RAJA: El trasero. La vagina.

REGAR: Estar tan emocionado sexualmente que se produce la autoeyaculación. En la mujer, cuando estando en similar condición, las glándulas inician la lubricación de la preparación en las paredes de la vagina (sic).

REJO: El pene.

ROSCA Y VUELTA: Vicio que consiste en ser durante un rato homosexual pasivo y después activo con la misma persona.

ROSCA la: El acto sexual. 
ROSCA: El recto.

SIETE el: El recto.

SODOMÍA: Relaciones Sexuales entre hombres [...].

SODOMAZO: Hombre con demasiada fama de homosexual [...].

SODOMA: Mujer homosexual o hermafrodita.

SORIA: Una tortilla (sic).

SORIAS echar: Relación sexual entre mujer y mujer. Frotación entre mujeres de los senos.

SORIADORA: Mujer que tiene fama de que le gustan las mujeres.

TAMAL qué: [...] cuando el joven en la cárcel tiene un trasero prominente [...].

TAPAS: Nalgas.

TAPAS dar las: Entregarse a otro hombre sexualmente.

TAPAS menudear las: Vender el cuerpo a otros hombres.

TAPONEAR: Hacer el acto sexual con otro hombre.

TAPÓN dar el: Entregarse por primera vez, hombre o mujer.

TARANTÍN el: El trasero.

TEMPLAR. Sentirse emocionado sexualmente.

TITI: Pene, vagina.

TORTILLAS: Acto sexual entre las mujeres.

TORTILLERA: Mujer que gusta de las mujeres.

TURCA la: Pene.

TUZA: Mujer de la vida.

TURRA: Mujer de la vida.

TRONCO, hasta el: La plenitud del acto sexual.

VASO hasta el: La plenitud del coito [...].

VERIJAS: Testículos.

VERGA: Pene.

VOLAR: [...] Proceder en las palabras, ademanes, como homosexual.

VOLADOR: Homosexual.

VOLAR REJO: Hacer el acto sexual [...].

VOLADORES: Varios homosexuales.

VUELTA Y ROSCA: Mutua homosexualidad. Este mutuo acuerdo de homosexualidad se lleva a cabo entre homosexuales activos [...].

ZORRA: Mujer de la vida que no aparece en los registros sanitarios o policiales. Es el principio de todas las prostitutas.

La obra de Sánchez Alvarado, como se señaló, no obedece con precisión a los criterios lexicográficos. Constituye más bien una lista de palabras y unidades léxicas en orden alfabético con peculiares definiciones; sin embargo, reviste una gran riqueza en sus valiosas y detalladas descripciones y explicaciones. Se puede observar que gran parte del vocabulario corresponde a lo sexual y que, a diferencia de Villegas (la distancia cronológica entre ambas obras es de siete años) y de Gagini, su interés era poner de relieve las acepciones de tipo sexual en su glosario, 
como él mismo señala en la cita que se recogió completa en la nota 4: "Aquí es bueno hacer notar que las denominaciones sobre el sexo es la colección más asombrosa que se puede reunir en el hampa tanto de la mujer como del hombre" (1960: 129).

Después de algunas décadas, en la de los años noventa vuelven a aparecer los diccionarios de costarriqueñismos, a saber, el Nuevo diccionario de costarriqueñismos, Quesada Pacheco (1991/2001) y el Diccionario de costarriqueñismos, de Agüero (1996). El primero incluye las siguientes palabras con acepciones sexuales:

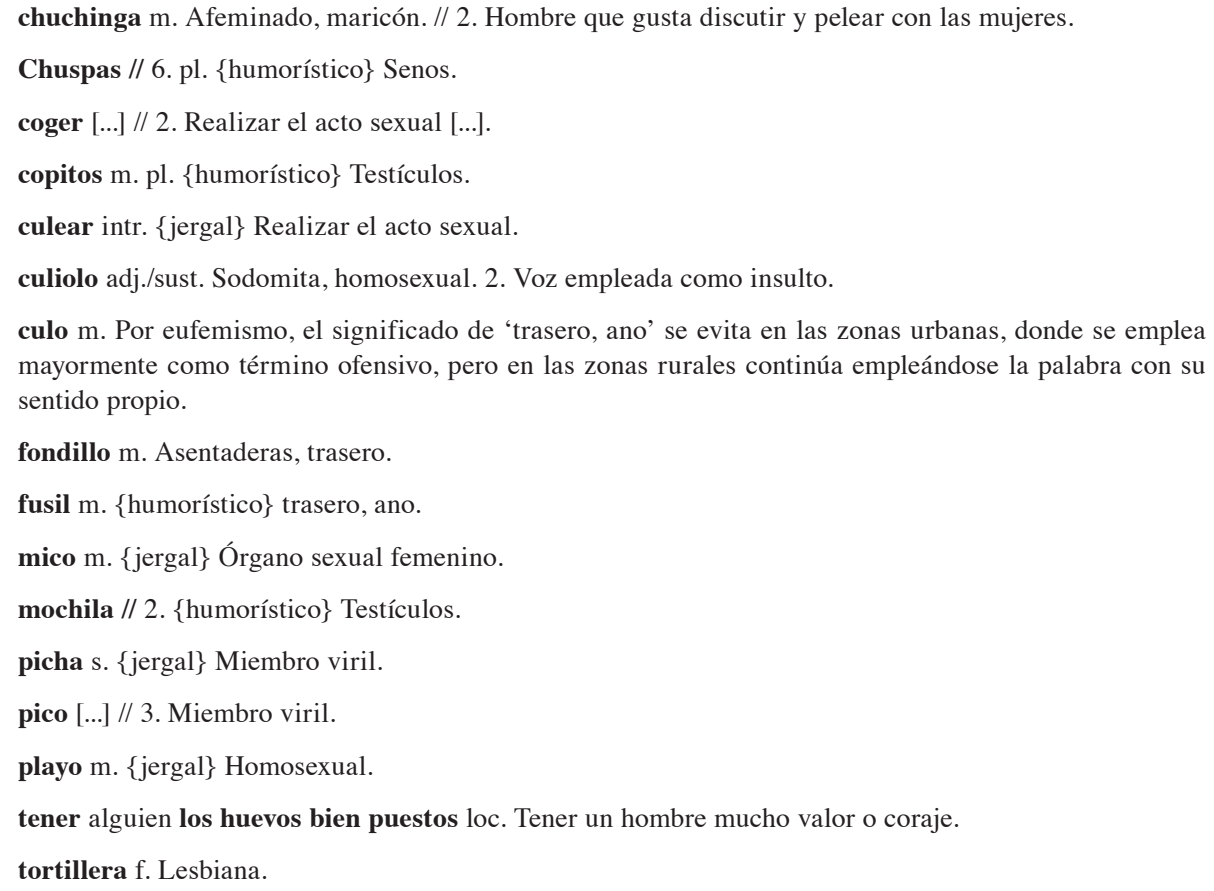

Se puede observar que, en el diccionario de Quesada Pacheco, se incluye ya la información lexicográfica que corresponde a cada entrada, y abarca algunas marcas sociolectales. Específicamente, respecto de tetas y puta, no hay referencias en este diccionario, por ser palabras panhispánicas. Sobre culo y huevos, también panhispánicas, la primera hace referencia en este diccionario solo a su sentido ofensivo o a su sentido propio, pero sí se registra en todos el costarriqueñismo fondillo; sobre huevos, solo aparece referida a un lexema pluriverbal, para indicar precisamente hombría, fortaleza masculina, pero sus significados primarios no aparecen. Esto se debe a que el autor mantiene el criterio de registrar los términos o las acepciones usados en Costa Rica puesto que, obviamente, se trata de un diccionario de voces costarricenses. Como cita Quesada Pacheco (1991/2001: Introducción), por ejemplo, sus datos presentan las siguientes condiciones:

palabras usadas en Costa Rica, registradas en el DEMM (Diccionario de uso del español, de M. Moliner) con cambios semánticos - por extensión de significado, por reducción de significado, por traslación de significado;

palabras registradas en el DEMM que en Costa Rica presentan cambios morfológicos en el género, en la derivación u otros;

palabras usadas en Costa Rica, pero registradas en el DEMM como propias de otros países o regiones hispanohablantes; 
palabras no registradas en el DEMM, entre las cuales hay -voces de origen incierto, desconocido o no determinado aún, voces de creación regional o local (sean o no de base castellana), préstamos y sus adaptaciones a la fonética del español costarricense.

A este respecto, el diccionario de Gagini también presenta criterios similares ${ }^{9}$. Sin embargo, Quesada Pacheco incluye picha, la cual la autora de este artículo presentó en su investigación como palabra del español general (huevos, tetas, culo, puta, tortillera, picha). Quesada Pacheco no incluye regarse en el Nuevo diccionario de costarriqueñismos, la cual utiliza la autora como una palabra de uso en Costa Rica.

Quesada Pacheco (1995) en su diccionario histórico, el cual contribuye "entre otras cosas, a registrar los primeros testimonios escritos de una palabra, a describir su forma y detectar su contenido", también presenta muy pocas referencias al vocabulario con connotaciones sexuales. Sin embargo, incluye algunas anotaciones; por ejemplo (1995: 36, 58, 115, 120):

COGER II tr. Cubrir el macho a la hembra (referido mayormente a los humanos). Cartago, 1724: la vieron venir sola de los montes y serros sin más vestuario que unas naguas por los hombros, maltratada, con ligaduras, dando vozes diziendo al d[ic]ho su padre: tatita, ya no sirvo, que tres hombres me an cogido y me an echado a perder (AECM: Fondos antiguos; caja 11, libro 2, fo. 409. El contexto anterior debe verse con cautela pues es ambiguo. El verbo coger podría también estar refiriéndose a la acción de 'asir', 'agarrar'.

CHUCHINGA adj. Afeminado (1892:DBPCR, p.230) Voz en vías de desaparición.

PANOCHA f. Empanada de harina grande y gruesa rellena. Manuel González. 1896: ña Regina con las muchachas, amasaba medio quintal de harina "Goldengate" haciendo rosquillas y panochas que iban colocando con primor en las "cazuelejas" llenas de manteca. (Cuentos. p. 79). La acepción con que ilustra C. Gagini el significado de panocha está tomada textualmente de un diccionario editado en Colombia (ver DC. p. 193). Y no calza con la empleada en Costa Rica hoy ni con el pasaje anterior que ilustra la definición. Hoy en día la palabra es usada en la jerga juvenil para designar la vagina, lo cual ha causado que la acepción primaria sea denominada con el término empanada.

PEPA f. "Pepita o pipa de algunas frutas." (1892: DBPCR. p. 492). "Pepita, pipa o almendra de algunas frutas, y en particular del chayote. del tacaco, etc. (1919: DC, p. 199). Hoy se emplea para designar únicamente las semillas del chayote y del tacaco; de donde ha pasado, por metáfora, a designar la vagina, como voz despectiva.

En las siguientes entradas, el autor no toma en cuenta que los términos son actualmente utilizados con una acepción sexual (1995: 97, 116):

MAMADA f. Ganga. ventaja que se obtiene sin costo. (1891:J. Fernández, Notas a los "Barbarismos guanacastecos”. p. 263; 1919: DC. p. 174; 1938: Vocabulario ... p. 91). Acepción en desuso hoy.

PARARSE ref. Ponerse de pie. San José, 1889: Se hinca de repente... En seguida no más se para y grita (El Gato: No. 2, 30-VII-1889, p. 3, col. 2).

Así, en lo relacionado con las acepciones históricas, Quesada Pacheco (1995) registra solo dos relativas al ámbito de lo sexual, a saber, coger y chuchinga.

Agüero (1996), con su diccionario llamado como el de Gagini, Diccionario de costarriqueñismos, es otro de los autores que incluye artículos de acepción sexual en su diccionario general sobre el español de Costa Rica. Registra algunos términos más que el diccionario anterior:

chuchinga. adj. fam. Afeminado, marica.//2. Cobarde, pusilánime.//3. Vagabundo.

chuspa. Fig. fam. Seno, mama, pecho, sobre todo si está caído. Ú.m.en pl.

conejo. m. vulg. Órgano sexual de la mujer, vulva [...]. 
culear. (De culo) intr. vulg. Tener cópula carnal.//prnl.vulg. Cubrir, poseer sexualmente a una mujer [...].

culiolo. m. vulg. Voz vitanda. Homosexual, sodomita.

empanada. [...] //fig. vulg. Vulva.

fondillo. (de fondo) m. fam. eufem. Culo, asentaderas, trasero. Es voz eufemística porque culo se considera palabra grosera y vulgar.//2. Ano.//Fondillos, parte trasera de los calzones o pantalones.//4. fam. Órgano sexual de la mujer.

fusil. m. fam. Ano, trasero, nalgas.

hacer tortillas. fr. fig. vulg. Ser homosexual una mujer.

huevo. [...] 2. Testículo.

mico. [...] //2. fig. vulg. Vulva, órgano sexual de la mujer. Con este significado es una de las palabras más vitandas.

mochila. //2. fig. fam. Testículo. U.m. en pl.

panocha. [...] //2. vulg. Vulva.

panocho. [...] m. vulg. Vulva.

perra. Adj. [...] mujerzuela, prostituta.

picha. f. vulg. Voz vitanda, pero vulgarmente muy común, para significar pene.

pinga. f. vulg. Miembro viril, pene, o miembro sexual de cualquier cuadrúpedo, simio, etc. machos.

playo. adj. vulg. Afeminado, homosexual.

polla. f. vulg. Pene.

putarrona. f. despect. Aum. De puta. Esa mujer es una PUTARRONA solapada.

tortillera. [...] // fig. vulg. Mujer homosexual.

venir. [...] prnl. Eyacular el semen un hombre, o sentir el orgasmo una mujer.

El autor incluye también algún vocabulario que la autora de la investigación presenta como de español general, como huevo, picha y tortillera, e incluye venir en la acepción en que la autora utilizó regarse, en el sentido de eyacular.

Por otro lado, el Nuevo diccionario del español de Costa Rica (manuscrito) recoge casi todos los términos aquí planteados, con sus respectivos sinónimos y algunos otros términos:

culeada: darle una $\sim$ a alg. coloq!! Tener relaciones sexuales con alguien. Obs: Voz usada especialm. Por los hombres.

culeado, -a adj. coloq!! Que ha tenido relaciones sexuales.

culear $v 1$ intr coloq!! Realizar la cópula carnal. I 2 se coloq!! Cubrir, poseer sexualmente el hombre a la mujer [sinón pisar]

culo $m 1$ coloq. Conjunto de las dos nalgas. I 2 coloq! Mujer muy hermosa y deseable sexualmente Obs: Debido a cierta restricción de uso por ser un término tabuizado, suele eufemizarse con vocablos como: rabo, tapas, chanchos, cul(antr)o, ramón.

huevos $m$ pl coloq. Testículos del hombre. Obs: También se aplica a las glándulas testiculares del animal [sinón bolas, copos, tolas].

mico $m$ coloq!! Panocho.

palo $m 4$ coloq!! Órgano sexual masculino.

panocho $m$ coloq!! Órgano sexual femenino; vulva [bizcocha, bizcocho, caregato, hendija, misingo, pancho, panocha]. Obs: Suelen formarse las expresiones coloquiales: "Parece rezo de pobre...solo bizcocho" y "Está como yo-yo sin manila... solo hendija". Pareciera que pancho se forma a partir de un fenómeno de síncopa a partir de panocho. 
perra I $f$ II sust/adj 2 coloq!! insult Mujer que acostumbra mantener relaciones sexuales con muchos hombres.

picha $f$ coloq!! Órgano genital masculino [sinón banano, guaba, leño, palo, pinga, sable, tuco, verga].

playo $m$ coloq!! Hombre homosexual o afeminado [sinón banano, carraco, culindingo, culiolo, guineo, platanazo, plátano, rábano].

puta $f$ coloq! desp insult Mujer que se dedica a la prostitución [sinón carretera, cuarenta, turra, zorra].

tetas f pl coloq! Senos de la mujer. Obs: Tiene eufemismos en: teresas, toronjas; cayendo en cierto desuso: chuspas, sobre todo si están flojos y caídos. Y también se usa para referirse a las ubres de la vaca u otra hembra animal. Asimismo, en lo que respecta a eufemismos, se forman las expresiones: ¡qué buenas te... nis!, ¡qué buen juego de té...!

tortillera $f$ coloq!! Mujer homosexual; lesbiana.

venir $v$ 1 se coloq!! Expeler el semen I 2 se coloq!! Sentir un orgasmo una persona.

zorra $f 1$ coloq! insult desp Mujer que mantiene relaciones sexuales con diferentes hombres. I 2 coloq! insult desp Mujer que tiene relaciones con diferentes, (sic) cobrando por ello determinada cantidad de dinero.

Este diccionario también registra las palabras del español general como puta, tetas y culo, puesto que incluye los sinónimos usados en el país. Además, registra marcas de estilo como "coloquial", "insultante", "despectivo" etc.

Por último, Arroyo Jiménez (1999) presenta en su Léxico del hampa costarricense, numerosos términos de connotación sexual, como los siguientes ${ }^{10}$ :

aguadito: quedar $\sim$ fun. v Lanzar con rapidez y fuerza el contenido de los testículos [destemplarse, irse, quedar débil, quedar flojo, quedar liviano, quedar vacío, regarse, salírsele el caldo, salírsele el lecherío, vacearse, vomitar].

alborotado,-a adj @ Referido al estado de excitabilidad erótica de una persona [templado,-a].

alforja $\mathrm{f} \sim \mathrm{s}$ Gónadas masculinas, generadoras de la secreción interna específica del sexo y de los espermatozoos [bolas, bolsas, bolinchas, cojones, huevos, marsmelos, tolas].

alita f Órgano sexual femenino [banco, bicho, bodeguita, cachimba, cartera, hueco, mico, moño, nato, panocha, peludo, pepa, raja, tajada, bisagra].

almohada $\mathrm{f} \sim \mathrm{s}$ Mamas de la mujer [chuspas, huevitos fritos, marsmelos, pellejero, tetas].

aplanchartr@Realizar el coito, copular [culear, hacer ñengue, hacerle bonito, pijar, pisar, poner de cuatro patas].

banano m Órgano genital masculino [bate, boli, cacho, curva, guaba, leño, maduro, mano de piedra, metráfora, narizón, paloma, picha, pinga, pitillo, posta, riel, rifle, tuco, verga].

bicolo m Varón que siente atracción por personas de su mismo sexo [cachero, cochón, comelón, loca, pájaro, playo, tragón].

botoncito m Eminencia cónica, eréctil, situada en el centro de la mama de las mujeres y en la que desembocan los conductos galactóforos [fresas].

cabada f Líquido producido por las glándulas genitales masculinas cuando se une a la secreción propia de la próstata. Está compuesto por espermatozoides, que se hallan en una suspensión coloidal, blanquecina, de olor característico [leche].

comilona f Mujer que siente atracción por personas de su mismo sexo [frustrada, soria, tortillera, tragona].

conejito m conjunto de órganos genitales masculinos [maleta, zapallo, zapote].

cuarenta f Mujer que lucra con sexo [percanta, puta, turra].

culo $\mathrm{m} \|$ poner el $\sim$ fun. v Utilizar el sexo para lucrar o conseguir algún beneficio. 


\begin{abstract}
dama del sexo func sust euf Mujer que lucra con sexo.
jalar v $3 \sim$ sela fun. v Autoestimularse el miembro viril un varón para proporcionarse goce sexual [echarse un sobo, sobársela].

mamar v ir Practicar el sexo oral una persona.

máquina $\mathrm{f} \sim \mathrm{de}$ hacer caca fun. sust Parte del cuerpo conformada por los glúteos. [maquinita].

paja: hacerse la $\sim$ func $v$ Autuoestimularse los órganos genitales o zonas erógenas con la mano o por otro medio para proporcionarse goce sexual. [pajearse].

pechonalidad f euf @ Mamas de la mujer [tentaciones, teresas, toronjas].

pipirigallo m Pequeño órgano femenino eréctil de gran excitabilidad sexual, situado en la parte elevada de la vulva.

pley: doble $\sim$ fun sust Persona que tiene inclinación por otras de su mismo sexo y de distinto sexo también.

pluma: botar $\sim \mathrm{s}$ fun $\mathrm{v}$ Mantener relación erótica dos hombres [regar plumas]. Mostrar un varón comportamiento afeminado [regar plumas].

polvo $\mathrm{m} 2$ Cópula sexual.

repellar v 1 tr Practicar contacto físico entre genitales sin llegar al coito. 2 Rozar intencionalmente, un hombre, con sus genitales a una mujer.
\end{abstract}

sodomo, -a sust / adj Persona que realiza actos sexuales con otra de su mismo sexo.

A pesar de que en su léxico Arroyo presenta numerosas voces con referencia a lo sexual, no se encontraron las utilizadas en la investigación de Calvo Shadid (2008).

\title{
3. Conclusiones
}

Como se puede observar en la cronología que se ha presentado, en diferentes momentos de los estudios lexicográficos costarricenses se han registrado términos o se han presentado acepciones del léxico sexual. En este tipo de estudios, se pueden determinar dos momentos: las obras anteriores a la década de los años noventa, y las que se han elaborado a partir de entonces.

El primer período, que abarca alrededor de cien años, iniciando con Gagini (1892), se presentan muy pocas referencias al vocabulario o a las acepciones de tipo sexual, a pesar de que las que se incluyen, principalmente en Gagini, son bastante específicas y descriptivas. Como excepción a esta tendencia se presenta la obra de Sánchez Alvarado (1960) sobre el léxico del hampa, recogido por él mismo en el presidio de San Lucas. No constituye un estudio con precisión lexicográfica; se trata, sin embargo, de un trabajo con gran riqueza documental: el autor recoge una gran cantidad de vocabulario del hampa utilizado en el presidio en aquella época, vocabulario muy usado en el habla coloquial actual. Registra una cantidad considerable de vocabulario de tipo sexual y abunda en descripciones, explicaciones y ejemplos. Por lo demás, sus comentarios personales en el propio estudio, describen el ambiente desgarrador, sexualmente hablando, del penal.

Posteriormente, el segundo período a partir de los años noventa, que abarca aproximadamente los últimos veinte años, presenta los títulos Nuevo diccionario de costarriqueñismos, de Quesada Pacheco (1991/2002), Nuevo diccionario del español de Costa Rica del proyecto ELEXHICÓS de la Universidad de Costa Rica (manuscrito), Diccionario de costarriqueñismos de Agüero (1996), y Léxico del hampa costarricense de Arroyo Jiménez (1999). Con ellos se inicia una nueva etapa de diccionarios y léxicos con minuciosas técnicas 
lexicográficas que incluyen, no solo suficientes entradas correspondientes al léxico sexual, sino también algunas acepciones tabuizadas y sinónimos.

Esta inclusión del tabú en los diccionarios regionales reviste gran importancia, puesto que el vocabulario de uso más frecuente en los estudios sociolingüísticos que se han llevado a cabo sobre el tema no permanece más velado ni en las sombras de lo "prohibido". Así, el porcentaje de uso del tabú sexual en el español de Costa Rica es de un 51,4\%"11, el más alto entre los estudios similares que se han elaborado en otras partes del mundo (Puerto Rico y Las Palmas de Gran Canaria), especialmente en el estilo informal, en el que el tabú se da en un $62,75 \%$ de los casos, porcentaje bastante elevado. Los resultados evidencian que el léxico tabuizado, en especial el que se refiere al tabú sexual debe ser estudiado y registrado debidamente, como se está haciendo en la actualidad, y no evadido o simplemente eliminado de los diccionarios y léxicos del español de Costa Rica y de otros países, como probablemente era la práctica de otras épocas.

\section{Notas}

1. Ver Calvo Shadid (2008).

2. Observar, por ejemplo, los trabajos de Vestad (1991), Martínez Valdueza (1995), López Morales (1990, 2005).

3. En este artículo se ha respetado la tipografía original de cada uno de los estudios presentados.

4. Tomado de http://www.acl.ac.cr/x.php

5. Especulación del autor.

6. El nombre del autor es José León Sánchez Alvarado, pero en esta obra, firma como José León Córdoba Sánchez.

7. A los diecinueve años de edad, José León Sánchez Alvarado fue enviado a la penitenciaría en la isla de San Lucas. Consiguientemente, la recopilación de los términos que aparecen en el glosario fue efectuada por él mismo como reo, por lo cual sus definiciones y comentarios revelan un carácter testimonial y se alejan de las formalidades lexicográficas.

8. Es interesante la digresión que hace el autor en esta entrada, en la que trata de demostrar cómo el léxico sexual (más que cualquier otro léxico) en un mismo grupo está sujeto a la variación espontánea y a la creatividad de los usuarios por el tabú que representa (1960: 129):

\footnotetext{
Aquí es bueno hacer notar que las denominaciones sobre el sexo es la colección más asombrosa que se puede reunir en el hampa tanto de la mujer como del hombre. En una conversación entre hampones supongamos que usted tenga una palabra totalmente nueva para el sexo: por ejemplo, DISCO VOLADOR. Entonces la conversación se inicia así: Llegué donde la mujer y ella me dijo que para darme el disco volador tenía antes que casarme con ella. Ya de inmediato todos los presentes saben y no preguntan más, que "el disco volador" es el sexo de la mujer, la vagina. La mente del criminal, extremadamente morbosa hasta la más acerba fantasía, está siempre pronta a aceptar cualquier giro dado al sexo. No sucede lo mismo con palabras aplicadas a otras cuestiones normales o de robos, etc. La mujer, la mujer como vicio, el sexo de la mujer como algo deseado por la abstinencia de las cárceles, lo han convertido en el hampón (sic) una palabra casi mítica. Ahora comprende el lector la imposibilidad de poner en estas páginas la gran cantidad de giros sexuales que acerva la lexicografía del hampa.
} 
9. Al respecto, cita Gagini (1892/75:11): [...] en ella (la edición) considero las divergencias de nuestro lenguaje con relación a la lengua madre, no solo como simples corruptelas, introducidas por el capricho o la ignorancia, sino como resultado natural de la evolución fonética y semántica a que están sujetos los idiomas vivos. Así mismo, Agüero (1996: Prólogo) señala: La investigación y estudio lingüísticos encomendados al autor de ella empezaron casi exclusivamente por el léxico del español costarricense, de acuerdo con sus diferencias de significado o significante, o de ambos a la vez, y tomando en consideración el estrato social del uso y la región geográfica de este.

10. Se colocan entre paréntesis [ ] los sinónimos referidos al término. Como referencia, se usará el primero en orden alfabético.

11. Según Calvo Shadid (2008).

\section{Bibliografía}

Agüero Chaves, A. 1996. Diccionario de costarriqueñismos. San José: Asamblea Legislativa de la República de Costa Rica.

Arroyo Jiménez, G. 1999. Léxico del hampa costarricense. Tesis de maestría. Universidad de Costa Rica.

Calvo Shadid, A. 2008. Análisis sociolingüístico sobre el tabú sexual en el español de Costa Rica. Tesis doctoral para optar por el grado de Dr. Philosophiae. Universidad de Bergen, Noruega.

Sánchez Alvarado, J. L. 1960. Glosario del hampa en Costa Rica. Colonia Agrícola Penal de San Lucas.

Gagini, C. 1892. Diccionario de barbarismos y provincialismos de Costa Rica. Tipografía Nacional.

1919. Diccionario de costarriqueñismos. Academia Costarricense de la Lengua. http:// www.acl.ac.cr/x.php. Consulta: 20 de marzo de 2011.

1919/1975. Diccionario de costarriqueñismos. San José: Editorial Costa Rica.

López Morales, H. 1990. Sociolingüística del tabú. El caso de Puerto Rico. Madrid: MS.

Martínez Valdueza, P. 1995. El tabú lingüístico: estudio sociolingüístico de Las Palmas de Gran Canaria. Tesis doctoral inédita. Las Palmas de Gran Canaria: Universidad de Las Palmas.

Proyecto ELEXHICÓS. (manuscrito). Nuevo diccionario del español de Costa Rica. Instituto de Investigaciones Lingüísticas, Universidad de Costa Rica. 
Quesada Pacheco, M.Á. 1991/2001. Nuevo diccionario de costarriqueñismos. Cartago: Editorial Tecnológica de Costa Rica.

Vestad, G. 1991. Análisis sociolingüístico del vocabulario malsonante castellano. Tesis de maestría inédita. Universidad de Oslo.

Villegas, Francisco. 1953. El argot costarricense. Tesis doctoral. University of Michigan. 